\title{
Understanding the Effectiveness of a Peer Coach Model in Research-intensive
} Undergraduate Courses

Michael J. Rovito, University of Central Florida, Michael.Rovito@ucf.edu

Amanda Koontz, University of Central Florida

Mary Tripp, University of Central Florida

Kim Schneider, University of Central Florida

Linda Walters, University of Central Florida

Martha Garcia, University of Central Florida

Abstract: The impact of peer coaches embedded in classrooms are outlined in the literature. There is, however, a lack of evidence on when their services should be introduced into the curriculum to have the most impact possible. The goals of this exploratory research project, therefore, were to aim to provide baseline evidence on the most effective and efficient application of 'Research Coaches'. A total of 129 undergraduate students took part in a cross-sectional design by completing a series of original surveys on the research process and qualities about their research identity. Our research suggests that peer coaches can most benefit those with the least previous research experiences as related to perceived increases in understanding of fields, research skills, previous knowledge of the subject of study and confidence in research abilities. Such quantitative findings are reinforced through our qualitative findings, suggesting that overall, peer coaches and faculty can be perceived as complimentary support systems for effective research-focused course implementation. Future implications of the use of 'Research Coaches' in the classroom are discussed.

Keywords: undergraduate research, peer coaches, curriculum, mentorship

While the benefits of undergraduate research are clearly supported in the literature, the difficulty in providing research opportunities is often related to a lack of support for faculty (Auchincloss et al., 2014; Gregerman et al., 1998; Morales et al., 2017). One way this has been addressed is through the use of peer coaches, sometimes called peer mentors (Budge, 2006; Linn et al., 2015). Schneider et al. (2015) suggest that undergraduate peer coaching, when integrated into learning communities, increases both GPAs and retention from the first into the second years in comparison to control groups without these experiences. Kim and Hannafin (2010) indicate another successful method to support faculty in fostering teaching excellence includes pedagogical scaffolding of undergraduate research throughout a specific curriculum [a specific illustration is the model developed within the concept of Higher Degree by Research (HDR)]. Other research on HDR has supported the supervision for one-on-one and the peer-to-peer learning practice lead undergraduates towards a more efficient preparation for postgraduate studies and job markets (e.g., Batty \& Sinclar, 2014).

Additional dialogue about peer-to-peer mentoring benefits focuses on the importance of the early practice of students' collaboration through co-authorship, emphasizing how students need to take on particular tasks of the "novice 
researcher" to start adopting the associated identity (Garbati \& Samuels, 2013: 367). This leads us to also reconsider the need for peer-to-peer collaboration from the earliest stages at the undergraduate levels. For example, in fields dedicated to the teaching and learning of second or multiple languages, peer-to-peer activities have constituted the grassroots of undergraduate language acquisition due to the need for constant interaction and communication among peers to reach the expected standards of proficiency and fluency (Kissau \& King, 2015). Pedagogical studies in teaching English as a second language have established, as well, the strong pillar of peer mentoring strategies (Nguyen, Thi Mai, \& Peter Hudson, 2012).

Quality of instruction through a more structured paradigm of mentoring has received special attention because of the necessary professionalization, especially critical thinking and communication skills, that the current job market demands and the need for comprehensive preparation for collegiate students to succeed in their chosen career paths (Reid, 2008). In combinations with diversifying student populations, the addition of undergraduate collaborative research experiences in higher education as early as possible may be particularly fruitful (Nguyen, 2017).

In considering the effectiveness of peer coaches, however, questions remain as to not just if an impact will occur as a result of the implementation of a peer coach model, but when should their services be introduced into the curriculum to have the most impact possible. As Sandoval (2017) indicates that the exposure to research experiences earlier in a given curriculum may augment students' epistemological beliefs, there is cause for concern that the effectiveness of a peer coach upon the highly-experienced students may be limited. Therefore, a key question arises with the implementation of a peer coach model within undergraduate courses: Are peer coaches more or less effective for students who have had previous exposure to the research process compared to those who have limited experience? In other words, would it be more effective to embed peer coaches into courses with undergraduate students who have less experience with the research process? The goals of this exploratory research project aim to provide baseline evidence on the most effective and efficient application of Research Coaches.

\section{Review of the Literature}

The following section reviews literature on prior findings on the implementation of various versions of peer mentoring/coaching models, offering context for the peer coaching model implemented for the purposes of this research study. Albeit not exhaustive, the summarized literature supports the integration of inquiry-based learning, authentic research, and high-impact opportunities throughout undergraduate college programs (Cahill et al., 2008; Guy \& Malenczyk, 2008; Ryan et al., 2008).

Extant literature indicates that the integration of research into the curriculum increases enhanced engagement with course content, higher quality outcomes, and skill development applicable for professional and/or graduate academic careers (Elmes, 2002). The literature also suggests that embedded peer mentoring for traditional undergraduate research may encourage higher retention rates, better 
professionalization, and enhanced engagement with course content (see Elmes, 2002; Reid, 2008; Schneider et al., 2015). These models, which have proven successful across curriculums in higher education institutions, can efficiently assist in contributing to the overall preparation of students during their college years and beyond graduation.

Other research indicates that embedding authentic research experiences, specifically in early stages of learning and throughout the entire student's tenure at the university, instead of just one or two semesters during their junior or senior years, have produced higher rates in the students' development of confidence and overall success (Schneider et al., 2015). However, in order to continually assess the efficiency of models and ascertain areas that may require some improvement, metrics need to be integrated into the development of the curriculum within and beyond the home institutions (Watson, Siska, \& Wolfel, 2013). Consequently, identifying and building a methodology of evaluation may contribute to a higher level of adoption of the coaching and mentoring norms that can help direct the focus of coaching. Norms facilitate teachers and learners grasp of the practicality and dexterity of applications and approaches (Kiefer \& Neufeld, 2002); as such, more research is needed that contextualizes undergraduate students' research experiences, in part to determine the norms of their experiences and thus to help direct the focus of peer coaching to improve effectiveness.

One gap in our understanding of peer coach success is understanding the background of students who would most benefit from taking a course embedded with the peer coach model, which we entitle an Embedded Peer Coach Course (EPCC). We, therefore, compared number of prior research experiences with perceived gains during the semester in courses involving embedded course research facilitated by a peer coach model. This information contributes to enabling decision-makers to focus the efforts of peer coaches within classes where impact can be maximized.

\section{Implementation and Methods}

\section{Design of the Peer Coaches Model}

The grounding for a systematic implementation of different styles of classroom strategies has generated new approaches in pedagogical applications (Song, 2016). In the process, specific rubrics for successful mentoring practices have been instrumental in the advance of enacting coaching and peer-to-peer collaboration, not only at the professional level in academia, but through its application in research-focused college experiences (Nguyen \& Mai, 2017). Therefore, an adapted version of a model developed at the University of North Carolina-Chapel Hill (UNC$\mathrm{CH}$ ) that focused on embedding graduate student research consultants into undergraduate courses (Pukkila et al., 2013) served as the framework for this study.

Four faculty members from a variety of disciplines at a large university in the southeastern U.S. participated in the application of the EPCCs. Research-focused 
courses were operationally defined as undergraduate courses that include a research component where students construct and complete their own semesterlong research project. The research component was required to include, but was not limited to, the following student activities: 1 ) creating a research question based on literature analysis, 2) developing research hypotheses, 3 ) developing $a$ priori methodological plans for hypothesis testing, 4) utilizing appropriate data collection and analysis methods for their field (or subject), and/or 5) communicating their project to their peers at annual campus undergraduate research showcase.

The EPCCs were designed for peer coaches to assist the enrolled students with embedded undergraduate research projects. Each faculty member was responsible for identifying, recruiting, training, and embedding their peer coaches into his or her EPCC. Criteria for peer coaches were flexibly defined as an advanced undergraduate or graduate student who possessed the skills necessary, as purported by the course instructor, to serve in the capacity of a coach. Each instructor was responsible for the preparation of the peer coach according to the demands of the course. Such assistance consisted of providing consult on core concepts of discipline-specific research, assistance in research project facilitation, guide in adjacent areas of knowledge required for genuine research experiences (i.e. writing and/or statistics counsel), or some combination of these tasks in the EPCC.

To study the effectiveness of the peer coach model in these EPCCs across all levels of student research, a pretest-posttest study design was employed to understand undergraduate students' perceptions of their: 1) understanding of the field, 2) research skills, 3) ability to conduct research. Our research aimed, therefore, to understand how peer coaches could most effectively support the implementation of research-focused undergraduate courses.

This research study was approved by the university's Institutional Review Board.

\section{Sampling Methodology}

All students enrolled in the EPCCs were asked to participate in the study. Following IRB guidelines, they were enrolled in the study if they were age 18 or older and provided appropriate consent. A total of 12 coaches were assigned to the courses: 3 coaches to modern languages, 2 coaches to composition, 4 coaches to health sciences, and 3 coaches to marine biology. The model had 1 coach per 15-20 students in the course to ensure that students had access to the resource and support regardless of the class size.

Peer coaches were considered volunteers in following institutional policies but were provided a financial award to support the following classroom research related activities: reimbursement of travel to an academic conference related to their research area, funding for research supplies, and/or reimbursement of travel costs to conduct research or creative activities. In the program at UNC-CH, graduate research consultants received a $\$ 1000$ stipend to support research-exposure course 
for a total of 30 hours over the course of the semester after attending a short training. The university where this current project was completed developed a version of this program that allowed both undergraduate and graduate students to serve as peer coaches in research-intensive courses for up to 30 hours of support during a single semester. Peer coaches received 6 hours of training by the team of faculty who developed the EPCC model prior to the start of the semester and a $\$ 500$ stipend.

Course enrollees were given participation credit for taking the survey, in accordance with the instructor guidelines. Students choosing to opt out of the study had the option to choose an open-ended questionnaire for participation credit during the same time students were completing the research surveys to preserve ethical principles. A research PI or Co-PI, that was not the instructor of record for the respective course, distributed surveys and questionnaires. They then also gave the instructor of record a list of all students present when the surveys and questionnaires were distributed for participation credit but were not informed as to their participation choice. This was done out of respect for issues of coercion and confidentiality.

\section{Instrumentation}

Original pre- and post-surveys were created via adapting an existing science identity tool (Anthony, Walters, \& McGrady, 2017) to measure similar concepts across a wider range of disciplines as it pertains to developing a research identity for all disciplines. The survey gathered information on students' research backgrounds (i.e., previous student experience), including if they had and, if so, the number of times they had: conducted a research project, participated universitywide research-based programming, attended a research conference, participated in service-learning, and/or had been a formal tutor/peer mentor. The questionnaire assessed attitudes and perceptions among participants pertaining to: 1) understanding of research in the field, 2) perceived research skills, 3) and perceived confidence in ability to conduct research. These three categories were assessed via a series of statements that the participant was asked to agree or disagree with on a scale of 0-10 where $0=N / A, 1$ meant strongly disagree, and 10 meant strongly agree. A series of 15 items made up the perceived research skills and perceived confidence in ability to conduct research composite variables, while 9 items made up the understanding of research in the field composite measure.

\section{Results}

The final sample size consisted of 129 students, as 129 of the total 149 eligible and consenting students completed both the pre- and post-survey $(86.57 \%$ response rate; see Table 1 for aggregate participant demographic information). The four courses had the following number of participants complete both pre- and post-test assessments: health sciences, 45 out of 55, modern languages, 9 out of 11, composition, 14 out of 22, and marine biology, 56 out of 60 . 
Table 1

Demographic Information of students who participated in the pre- and postquestionnaire.

\begin{tabular}{lll}
\hline Variable & Category & Percentage (\%) \\
\hline Age & $18-20$ & 26.8 \\
& $21-23$ & 58.5 \\
& $24-26$ & 9.8 \\
Race/Ethnicity & $27+$ & 4.9 \\
& White/Caucasian & 65.9 \\
& Black/African-American & 4.8 \\
& Asian/Pacific Islander & 5.7 \\
& Native American/ Alaskan Native & 1.6 \\
Hispanic & Multiracial/Mixed & 3.2 \\
Sex & Did Not Indicate & 18.8 \\
& YES & 19.4 \\
& Male & 32.5 \\
\hline
\end{tabular}

To explore the effect of embedded peer coaches in an EPCC, participants were categorized into groups according to their self-reported previous experiences with research to determine if this impacted results. Five items operationalized previous student experience, including if, at the time of entering the course, they had any research background previously in their undergraduate career, as mentioned previously. Participant responses indicating 'yes' to any of the 5 items were summed up to represent a raw experience score. Participants were further categorized into: "no previous", "one previous", "two previous", and "three to five previous" experience (see Table 2).

Table 2

Percentage of Previous Experience Categories

\begin{tabular}{lll}
\hline Variable & Category & Percentage (\%) \\
\hline Previous Experience & No previous & 33.3 \\
& One previous & 34.1 \\
& Two previous & 16.3 \\
& Three to five previous & 16.3 \\
\hline
\end{tabular}

\section{Understanding of Research in the Field}

A total of 9 items that assessed participant familiarity and knowledge of research topics and ideas operationalized the Understanding of Research in the Field construct. Participant responses on both the pre- and post-survey were summed and then divided by the total number of items to calculate an average score. A Wilcoxon paired sampled means test indicated that only the 'one previous 
experience' group exhibited a statistically significant increase in scores from pre- to post-test (Table 3).

Table 3

Understanding of Research in the Field Pre-Post Analysis

\begin{tabular}{lllll}
\hline Variable & $\begin{array}{l}\text { Previous experience } \\
\text { category }\end{array}$ & Baseline $\overline{\boldsymbol{x}}$ & Postest $\overline{\boldsymbol{x}}$ & $\begin{array}{l}\text { Wilcoxon } \\
\text { p-value }\end{array}$ \\
\hline $\begin{array}{l}\text { Understanding } \\
\text { research in }\end{array}$ & None & 7.29 & 7.46 & .536 \\
the field & & & & \\
& One & 7.29 & 8.01 & $.006 *$ \\
& Two & 7.84 & 7.96 & .372 \\
& Three to five & 8.38 & 7.77 & .436 \\
\hline
\end{tabular}

* Denotes statistical significance @ $p \leq 0.05$

An independent samples Kruskal-Wallis Test (Table 4) indicated baseline and posttest significant differences in mean scores present across 'previous experience' groups. Dunn's test post-hoc analyses indicated that, at the start of the semester, those students who had no or one previous experience had statistically significant mean score differences as compared to those students who had three to five previous experiences. Post-test analyses indicted that although a significant difference existed across all groups, at the end of the semester only the 'no previous experience' group had a significant difference compared to those with three to five previous experiences. This reveals that the 'one previous experience' and 'two previous experience' groups shifted enough to not significantly differ from the 'three-to-five experience' group.

Table 4

Understanding of Research in the Field Between-Group Analysis

\begin{tabular}{llll}
\hline Variable & Previous experience category & Baseline $\overline{\boldsymbol{x}}$ & Postest $\overline{\boldsymbol{x}}$ \\
\hline Understanding & Between Experience groups & $0.13^{*}$ & $.043^{*}$ \\
research in & All Groups & \\
the field & & \\
& Between Individual Experience groups (Dunn's post-hoc) \\
& No to One experience & .708 & .169 \\
& No to Two experiences & .292 & .529 \\
& No to Three to Five experiences & $.006^{*}$ & $.005^{*}$ \\
& One to Two experiences & .174 & .645 \\
& One to Three to Five experiences & $.002^{*}$ & .090 \\
& Two to Three to Five experiences & .143 & .067 \\
\hline
\end{tabular}

* Denotes statistical significance @ $\mathrm{p} \leq 0.05$ 


\section{Perceived Research Skills}

A total of 15 items assessing perceived skills needed to conduct research were used to operationalize Perceived Research Skills. Participant responses on both the preand post-survey were summed and then divided by the total number of items to calculate an average score.

A Wilcoxon paired sampled means test indicated that all groups, except the three to five previous experiences group, exhibited statistically significant increases in their scores from pre- to post-test (Table 5).

Table 5

Perceived Research Skills Pre-Post Analysis

\begin{tabular}{lllll}
\hline Variable & $\begin{array}{l}\text { Previous experience } \\
\text { category }\end{array}$ & Baseline $\overline{\boldsymbol{x}}$ & Postest $\overline{\boldsymbol{x}}$ & $\begin{array}{l}\text { Wilcoxon } \\
\text { p-value }\end{array}$ \\
\hline Previous & No & 7.29 & 7.46 & $<.001^{*}$ \\
research skills & & 7.29 & 8.01 & $<.001^{*}$ \\
& One & 7.84 & 7.96 & $.030^{*}$ \\
& Two & 8.38 & 7.77 & .895 \\
\hline
\end{tabular}

* Denotes statistical significance @ $p \leq 0.05$

An independent samples Kruskal-Wallis Test (Table 6) results indicated only baseline significant differences in mean scores present across 'previous experience' groups. Dunn's test post-hoc analyses indicated that, at baseline, those students who had no or only one previous experience had statistically significant mean score differences as compared to those students who had two previous experiences and three to five previous experiences. There were no statistically significant different scores at post-test across the previous experience groups.

Table 6

Perceived Research Skills Between-Group Analysis

\begin{tabular}{llll}
\hline Variable & Previous experience category & Baseline $\overline{\boldsymbol{x}}$ & Postest $\overline{\boldsymbol{x}}$ \\
\hline Previous & Between Experience groups & $<.001^{*}$ & .157 \\
research skills & Al/ Groups & \\
& & \\
& Between Individual Experience groups (Dunn's post-hoc) \\
& No to One experience & .189 \\
& No to Two experiences & $.001^{*}$ \\
& No to Three to Five experiences & $<.001^{*}$ \\
& One to Two experiences & $.027^{*}$ \\
& One to Three to Five experiences & $.004^{*}$ \\
& Two to Three to Five experiences & .571 & \\
\hline
\end{tabular}

* Denotes statistical significance @ $\mathrm{p} \leq 0.05$ 


\section{Perceived Confidence in Ability to Conduct Research}

A total of 15 items that assessed participant perceived ability in the field operationalized the Perceived Research Ability construct. This construct helps to differentiate between their perceived research skills and their confidence in actually applying those skills. Participant responses on both the pre- and post-survey were summed and then divided by the total number of items to calculate an average score.

A Wilcoxon paired sampled means test indicated that the no previous and one previous experience groups exhibited statistically significant increases in their scores from pre- to post-test (Table 7). With two research experiences, the results were marginally significant $(p=0.77)$.

Table 7

Perceived Research Ability Pre-Post Analysis

\begin{tabular}{lllll}
\hline Variable & $\begin{array}{l}\text { Previous experience } \\
\text { category }\end{array}$ & Baseline $\overline{\boldsymbol{x}}$ & Postest $\overline{\boldsymbol{x}}$ & $\begin{array}{l}\text { Wilcoxon } \\
\text { p-value }\end{array}$ \\
\hline Previous & No & 4.87 & 6.89 & $.001^{*}$ \\
research ability & One & 5.43 & 7.30 & $<.001^{*}$ \\
& Two & 6.86 & 7.34 & .077 \\
& Three to Five & 7.06 & 7.41 & .801 \\
\hline
\end{tabular}

* Denotes statistical significance @ $\mathrm{p} \leq 0.05$

An independent samples Kruskal-Wallis Test (Table 8 ) results indicated only baseline significant differences in mean scores present across 'previous experience' groups. Dunn's test post-hoc analyses indicated that, at baseline, those students who had no previous experience had statistically significant mean score differences as compared to those students who had two to five previous experiences. There were no statistically significant different scores at post-test across the previous experience groups.

Table 8

Perceived Research Ability Between-Group Analysis

\begin{tabular}{llll}
\hline Variable & Previous experience category & Baseline $\overline{\boldsymbol{x}}$ & Postest $\overline{\boldsymbol{x}}$ \\
\hline Previous & Between Experience groups & $<.006^{*}$ & .055 \\
research ability & Al/ Groups & \\
& Between Individual Experience groups (Dunn's post-hoc) \\
& No to One experience & .235 \\
& No to Two experiences & $.005^{*}$ \\
& No to Three to Five experiences & $.004^{*}$ \\
& One to Two experiences & .067 \\
& One to Three to Five experiences & .053 \\
\hline
\end{tabular}




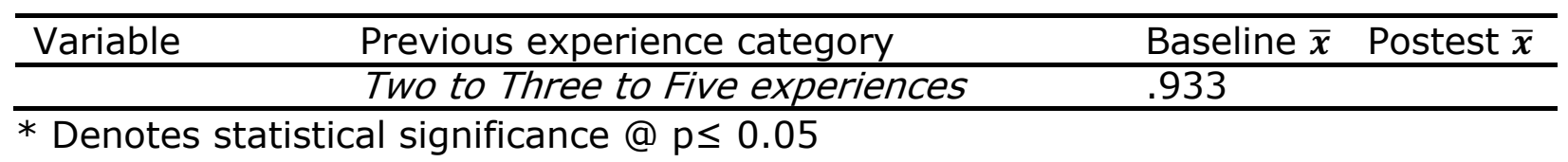

\section{Semesters Attended}

Students were also categorized by how many semesters they attended university: $0-3$ semesters, $>3$ to $<6$ semesters, $>6$ to $<8$ semesters, and $>8$ semesters. At baseline, there were statistically significant differences across groups regarding perceived research skills and ability. However, no post-test significant differences were reported.

Wilcoxon paired sampled means test indicated that there were statistically significant differences pre- to post-test in the $0-3$ and the $>3$ to $<6$ semesters attended group for perceived research skills and perceived research ability. The $>6$ to $<8$ group demonstrated significant pre- and post-test scores in understanding of research in the field and perceived research skills. Finally, the $>8$ semesters attended group had significant pre- to post-test scores for all three categories (i.e. understanding of research in the field, perceived research skills, and perceived research ability).

\section{Psychometric Analysis of Instrument}

A principal components confirmatory factor analysis was run on the three a prioridefined sections: Understanding of Research in the Field, Perceived Research Skills, and Perceived Research Ability. Three factors were produced that mirrored the original survey composite variables. Low communality on extracted factors present and Cronbach's scores of $a=.976, a=.944$, and $a=.822$, respectively, offered construct validity and internal consistency to the data. Content and face validity was confirmed through peer-conferencing techniques on survey creation.

\section{Discussion and Implications}

In examining how to effectively implement peer coaches, the findings of this research suggest that although multiple groups benefit, those with the fewest research experiences revealed the most significant changes in areas related to research identities. The findings suggest that students in EPCCs with the fewest previous research experiences benefit the most from peer coaches in undergraduate courses, as defined by shifts in perceived understanding of research in the field, research skills, and confidence in ability to conduct research. These findings support prior research that suggests that students and peer mentors benefit from integrating inquiry-based learning, authentic research, and high impact opportunities throughout the undergraduate college programs (Cahill et al., 2008; Guy \& Malenczyk, 2008; Reid, 2008; Ryan et al., 2008). In addition, our research offers viable recommendations for how peer coaches can be effectively implemented across disciplines, highlighting the commonalities for how to implement such a peer coach model. 
While we know that genuine research experiences produce higher rates in the students' development of confidence and overall success (Schneider et al., 2015), this research expands our understanding to suggest that delimiting resources for coaches may be targeted for larger, lower level undergraduate courses because of the increased likelihood to have a significant impact. It is also logical that the use of peer coaches help faculty integrate these authentic research experiences in college classrooms. Our research brings these two pedagogical practices together, reinforcing Anthony, Walters, and McGrady's (2017) findings, suggesting benefits from an increase in their perceptions of themselves as more confident, motivated, engaged, knowledgeable, and skillful at research as the result of interacting with peer coaches.

Our study demonstrates that increasing the support for a course design that involves peer coaches, especially in the early years of an undergraduate degree, can potentially lead to better learning outcomes for these students, which can eventually lead to increased "career-readiness" among the student body. To support the findings from this study, further research into the effects of peer coaches in early undergraduate courses will still be needed, recommended, and beneficial. Peer coaches may be particularly effective because of: 1) their perceived help with the research process, 2) their accessibility to allow those with less experiences more availability to ask core questions on the research process that they may otherwise be embarrassed to ask the professor, and 3) their allowing for a leveling on topics that those with greater experiences already have had exposure to in their prior research. These points additionally give the professor more time to answer questions on areas of disciplinary expertise, which may be more helpful to those with more prior experiences.

Some limitations of our study include the lack of a control group to truly highlight the possible causal pathway between the implementation of this model and benefits to the student body. Therefore, future studies could more specifically focus on potential applications and causal mechanisms driving the positives of this peer coach model. For example, we know women and minority students are particularly receptive to mentoring; to adopt an intersectional approach to researching the interconnections across demographics (Crisp \& Cruz, 2007; Gibbons \& Woodside 2014). Further examination of how demographic and cultural background characteristics potentially intersect (e.g., gender, race/ethnicity, SES, firstgeneration, etc.) and influence the effectiveness of EPCCs would be especially beneficial. EPCCs may be an additional bridge for transfer students adjusting to a larger scale of educational systems; as based in the particularly large university at which this study took place, there is a distinct possibility that the peer coaching model is a viable option for helping diverse student populations navigate transitions into and through classes where they may otherwise not feel integrated into the classroom.

Some other limitations of the study include the regression artifact threat. As regression to the mean stems from in large part a nonprobability sample, there is little that could be done to correct for this possible source of systematic error. Students cannot be randomly selected from the university population and then 
allocated to course sections, let alone across different discipline's courses. Future applications can attempt to remedy this issue but may prove methodologically difficult. Also, the amount of time and the exact use of the coaches will differ across each course that embeds them into the course. This does not provide a uniformity of use and then may detract from the general effectiveness of the coaches per course. Future studies should look at the effectiveness of coach application to determine best practices.

The combination of peer coaches and research experiences seems to offer an effective response to the economic constraints challenging the diversification of the academic community who wish to maintain a sustained high level of integrity, interaction, and participation among undergraduate students in early years of college experience and their counterpart faculty members. In particular, it appears that peer coaches especially help students in developing research skills, so that there are possibilities for effective usage across student populations. Such distribution can offer insight into, for example, whether it can be more effective to have peer coaches in early programming versus capstone, since students may have increased experience at that given point. However, as our research still shows significant shifts across the three assessment categories for students with more than 8 semesters, it may be that coaches serve a different purpose in helping students who have attended school longer develop research skills specifically, since they already have started to develop disciplinary expertise. Additional research can also explore whether the leveling across research experiences is due to an increased practical understanding of their knowledge in skills; this, in turn, may substantially increase their retention in their fields because they are able to match their abilities with practical application and needs for further skill development.

To summarize, our research suggests that peer coaches can most benefit those with the least previous research experiences as related to perceived increases in understanding of fields, research skills, previous knowledge of the subject of study and confidence in research abilities. Such quantitative findings are reinforced through our qualitative findings, suggesting that overall, peer coaches and faculty can be perceived as complimentary support systems for effective research-focused course implementation. In effectively implementing this model, coaches can be understood as accessible and approachable peer mentors that offer the first line of support for research projects, while faculty members can have the additional time to go in-depth with students on expertise, specialized knowledge and content.

\section{Acknowledgments}

This research was funded by our university's offices of Undergraduate Research and Quality Enhancement Plan during the academic year of 2014-2018.

\section{Conflicts of Interest}

The authors declare that there is no conflict of interest regarding the publication of this article. 


\section{References}

Auchincloss, L. C..., Laursen, S. L., Branchaw, J.L., Eagan, K., Graham, M., Hanauer, D.I., . . . Dolan, E.L. (2014). Assessment of course-based undergraduate research experiences: A meeting report. CBE-Life Sciences Education 13(1): 29-40.

Anthony, A. K., Walters, L. J., \& McGrady, P. (2017). Creating connections between authentic research and the development of science identities in undergraduate Marine Biology experiences. Florida Scientist 80(2-3): 61-76.

Ariza, A., \& Viáfara González, J.J. (2009). Interweaving autonomous learning and peer-tutoring in coaching EFL student-teachers/La conexión entre aprendizaje autónomo y la tutoría entre pares como apoyo a estudiantes de inglés como lengua extranjera. Profile 11(2); 85-104.

Batty, C. \& Sinclair, J. (2014). Peer-to-peer learning in the higher degree by research context: a creative writing case study. New Writing 11(3); 335-46.

Budge, S. (2006). Peer mentoring in postsecondary education: Implications for research and practice. Journal of College Reading and Learning 37(1): 71-85.

Cahill, L., Miller-Cochran S., Pantoja, V., \& Rodrigo, R.L. (2008). Graduate student writing groups as peer mentoring communities. In M. F. Eble \& L. L. Gaillet, (eds.) Stories of mentoring: Theory and praxis (pp.153-58) Anderson, SC: Parlor Press

Crisp, G., \& Cruz, I. (2009). Mentoring college students: A critical review of the literature between 1990 and 2007. Research in Higher Education 50(6): 525545.

Elmes, D.G. (2002). Lab courses for undergraduates: The benefits are clear. APS Bulletin 15(7): 13-40.

Garbati, J. \& Samuels, B. (2013). Publishing in educational research journals: are graduate students participating? Journal of Scholarly Publishing 44(4): 35572.

Gregerman, S. R., Lerner, J. S., Hippel, W., Jonides, J. \& Nagda, B. A. (1998). Undergraduate student-faculty research partnerships affect student retention. The Review of Higher Education 22(1): 55-72.

Gibbons, M. M., \& Woodside, M. (2014). Addressing the needs of first-generation college students: Lessons learned from adults from low-education families. Journal of College Counseling 17(1): 21-36.

Guy, A. E., Jr. \& Malenczyk, R. (2008). A new paradigm for WPA mentoring? The case of New York University's expository writing program. In M. F. Eble \& L. L. Gaillet, (eds.) Stories of mentoring: Theory and praxis (pp. 235-47) Anderson, SC: Parlor Press.

Hamilton, D. (1977). Writing coach. College Composition and Communication 28(2): 154-58. 
Healy M. \& Jenkins A. (2009). Developing undergraduate research and inquiry. New York, NY: The Higher Education Academy.

Kiefer, K. \& Neufeld, J. (2002). Making the most of response: reconciling coaching and evaluating roles for teachers across the curriculum. Academic Writing: Interdisciplinary Perspectives on Communication across the Curriculum. https://wac.colostate.edu/aw/articles/kiefer_neufeld_2002.pdf.

Kim, M. \& Hannfin M. (2011). Scaffolding problem solving in technology-enhanced learning environments (TELEs): Bridging research and theory with practice. Computers and Education 56: 403-417.

Kissau, S. P. \& King, E. T. (2015). Peer mentoring second language teachers: a mutually beneficial experience? Foreign Language Annals 48(1): 143-60.

Linn, M. C., Palmer, E., Baranger, A., Gerard, E. \& Stone, E. (2015). Undergraduate research experiences: Impacts and opportunities. Science 347(6222): DOI: $10.1126 /$ science. 1261757.

Morales, D. X., Grineski, S. E., \& Collins, T. W. (2017). Faculty motivation to mentor students through undergraduate research programs: a study of enabling and constraining factors. Research in Higher Education 58(5): 520544.

Nguyen, H. T. M. \& Hudson, P. (2012). Peer group mentoring: preservice EFL teachers' collaborations for enhancing practices. In A. Honigsfeld, \& M. G. Dove (Eds.), Coteaching and Other Collaborative Practices in the EFL/ESL Classroom: Rationale, Research, Reflections, and Recommendations (pp. 231-40). Charlotte, NC: Information Age Publishing.

Nguyen, H. T. M. (2017). Models of mentoring in language teacher education. New York, NY: Springer.

Perlman B. \& McCann L. (2005). Undergraduate research experiences in Psychology: A national study of courses and curricula. Teaching of Psychology 32(1): 5-14.

Pukkila P., Arnold M., Li A., \& Bickford D. (2013). The graduate research consultant program: Embedding undergraduate research across the curriculum. CUR 33(4): 28-33.

Ryan, H, Reamer, D. Enos, T. (2008). Narrating our revision: a mentoring program's evolution. In M. F. Eble \& L. L. Gaillet, (eds.) Stories of mentoring: Theory and praxis (pp. 289-300) Anderson, SC: Parlor Press.

Reid, E. S. (2008). Mentoring peer mentors: mentor education and support in the composition program. Composition Studies 36(2): 51-79.

Sandoval, C. (2017). The Impact of Undergraduate Research Experience: A Focus on Special Consideration Students. Poster. Panoma, CA: Southern California Conference for Undergraduate Research.

Schneider, K. R., Bickel, A., \& Alison Morrison-Shetlar, A. (2015). Planning and implementing a comprehensive student-centered research program for first- 
year STEM undergraduates. Journal of College Science Teaching 44(3): 3743.

Song, K. H. (2016). Systematic professional development training and its impact on teachers' attitudes toward Ells: SIOP and guided coaching. TESOL 7(4): 76799. 